\title{
Transforming Dialogue Journal Writing Into Pedagogy of Online Setting: A Preliminary Study
}

\author{
Bambang Yudi Cahyono \\ Universitas Negeri Malang \\ Zhenita Deliany \\ Universitas Negeri Malang
}

Dialogue Journal Writing (DJW) has been implemented in the writing classroom for more than twenty-five years. Currently, however, research studies are not limited to DJW as a medium for communication but also on the role of DJW in developing language learners' writing proficiency. Interestingly, while technology has developed fast, the application of technology on DJW is a rare undertaking. Therefore, this study investigated the potentials of the transformation of Dialogue Journal Writing into Online dialogue Journal Writing (ODJW). More particularly, it focused on writing productivity and students' perception of ODJW efficacy. This study involved 22 EFL students who took Paragraph Writing course at a reputable university in East Java, Indonesia. They were involved in ODJW in five sessions which were conducted asynchronously by using a combination of WhatsApp and E-mail applications. The results of this preliminary study shows that ODJW was potential in terms of productivity in writing. In addition, the learners perceived that the implementation of ODJW was a beneficial activity and it makes the students happy.

Keywords: EFL students, online dialogue journal writing, writing productivity

\section{INTRODUCTION}

One of the interactive writing activities which were applied for the communicative purpose was dialogue journal writing (DJW). In DJW, language learners could write anything interesting in their journals. Meanwhile, the teachers provided responses to the messages conveyed in the journals without evaluating the linguistic aspects such as grammar, vocabulary, or mechanics. Research studies have examined the role of dialogue journal writing (DJW) in helping students write better in a second or foreign language. In the past, it was believed that DJW was aimed to help students write more fluently. In their handbook for teachers in managing DJW, Peyton and Reed (1990) stated:

Students write regularly in the journal, as much as they want and about whatever they choose, and the teacher writes back - not grading or correcting the writing, and not responding with simple platitudes or evaluative comments such as "Good" or "Interesting point!" The teacher is a partner in a conversation ... (pp. 3-4, emphasis original) 
Currently, a number of studies (e.g. Al Kayed, Alkayid \& Alsmadi, 2020; Dabbagh, 2017; Hapsari, Susilohadi \& Elyono, 2018; Safari, 2020) investigated whether or not DJW was effective in increasing students' writing skills. For instance, Al Kayed et al. (2020) investigated the effect of DJW on the writing skills of Jordanian learners of English as a foreign language (EFL). The study examined the difference in the students' attitudes towards writing before and after the implementation of DJW. The results of the study revealed that not only improve students' writing skills and its subcomponents, namely vocabulary, organization, and grammar, DJW also developed students' positive attitude towards writing after getting exposed to it.

Al Kayed et al. (2020) have, in fact, supported the successful results of several studies conducted earlier. Dabbagh's (2017) study revealed that DJW positively affected students' writing performance and writing components except for language use and mechanics. DJW offered an orderly regular writing practice, leading L2 writers to make a connection to what they are writing about on their topic of interest. As a result, the contribution of the regular writing practice was seen in the improvement of learners' writing performance. In their action research, Hapsari et al. (2018) applied DJW, and the students' journals were responded to regularly. They found that DJW played a role in improving students' writing proficiency as well as their participation as long as several considerations were taken into account. First, teachers provided students with a clear explanation about the concept of DJW. Second, teachers gave a guideline to the students to start writing. Third, students received adequate grammar practices. Fourth, the teachers used various types of feedback. Thus, DJW could improve students' writing proficiencies and made them learn with high engagement.

Recent practices mentioned above reflected the use of "a bound notebook" and the like as the basic medium in DJW emphasized by Peyton and Reed (1990). This is contradictory with the development of information and communication technology (ICT), especially the Internet, which offers various digital applications that could be used in DJW. However, our literature review brought us only two research studies on online dialogue journal writing (ODJW). A study on the use of a Learning Management System (LMS) in dialogue journal writing conducted by David, Azman, and Ming (2018) proved that ODJW could reduce writing anxiety among low proficiency ESL undergraduate students at a Malaysian public university. The result of ODJW intervention caused the students' writing anxiety decreased from high to a moderate level and some to low level of anxiety. Noyan and Kocoglu (2019) utilized a mobile phone application WhatsApp as the medium of dialogue journal writing. The ODJW using WhatsApp was compared to the traditional DJW. The results revealed that both ways of dialogue journal writing showed a significant effect on writing performance. Thus, the studies ODJW suggested the importance of the integration of technology especially e-learning platform and social media in the two-way communication between students and the teacher in dialogue journal writing.

In light of the background on research in DJW and the limited research on ODJW, the present study aimed to examine the effect of ODJW on EFL students' writing productivity by using the combination of WhatsApp and E-mail and see what they perceive on the application of ODJW. The research questions as stated as follows:

(1) Is there any improvement in the EFL students' writing productivity after being taught by using ODJW?

(2) How do the EFL students perceive the application of ODJW in the teaching of paragraph writing?

\section{REVIEW OF LITERATURE}

Regardless of the modes in the application of DJW, be it traditionally or through online applications, practices in DJW are supported by second language acquisition (SLA) and socio-cultural theories. As explained by Rana (2018), in SLA, the theories underlying DJW cover the monitor model hypothesis, affective filter hypothesis, interaction hypothesis, and output hypothesis, while the socio-cultural theory was the Zone of Proximal Development (ZPD). The feature of written conversation in dialogue journal benefits students because there is no overt correction in DJW. Based on the monitor model hypothesis, 
learners can give better output if they are not involved in editing their language before they produce it. Accordingly, students are motivated to express their feelings and interests without being afraid of correction or evaluation. The learners' motivation to write and their self-confidence can neglect the mental blocks that hinder their language acquisition (affective filter hypothesis). Then, students' critical, creative, active communication and opportunity to build rapport with their peers and teachers all together are seen as some sorts of interactions with others that serve language acquisition (interaction hypothesis). In terms of output hypothesis, the product of DJW is perceived as language production in which language and acquisition may occur. From a socio-cultural perspective, dialogue journals support the notion of ZPD that learning accelerates through collaboration, interaction, and assistance (Saville-Troike, 2006).

Research studies have explored how DJW relates to psychological factors and learners' personalities (Konishi \& Park, 2017; Madeng \& Palanukulwong, 2019). It is believed that DJW, which entails a studentteacher conversation over time, promote positive social-emotional learning (SEL) for students at school (Konishi \& Park, 2017). This happens because dialogue journals facilitate students and the teacher to establish trust, which encourages individual concerns. Besides, both students and the teacher can find what they can do to improve their lives due to unlimited topics that can be addressed in the dialogue journal. More importantly, there is a sense of ownership in learning which rises from the interaction. As Konishi and Park (2017) argue, this makes students more autonomous toward their academic and interpersonal lives. A survey by Madeng and Palanukulwong (2019) revealed that students had positive attitudes towards writing in English, the use of DJW, and they were more willing to write after the implementation of DJW. They also perceived that dialogue journals represent a genuine conversation that provided an anxiety-free atmosphere in their writing classes.

Unlike the early practice in DJW in which there was no correction in the way the learners write (Peyton \& Reed, 1990; Baskin, 1994), some studies attempted to describe the types of feedback provided in DJW and the effect of grammar feedback in DJW. For example, Nuramirah (2017) conducted a study to investigate the types of corrective feedback the teacher provided in a dialogue journal. The findings revealed that the most frequent errors made by students were grammatical errors. The teacher helped the students to correct their grammatical errors through several types of corrective feedback, two of which were the most frequently used, namely explicit and metalinguistic corrective feedback. The explicit corrective feedback was the most frequently used for elementary-level students, while metalinguistic feedback was most frequently used for intermediate-level students. However, the most frequent uptake made for the elementary and intermediate level students was explicit corrective feedback. The research conducted by Hapsari et al. (2018) also showed that grammar was one of the language components positively affected by the feedback given in the dialogue journal writing. Their action research showed that students' grammar score measured at the end of the first cycle increased $7 \%$ from the result of the pretest, and then the students' score measured at the end of the second cycle increased $13 \%$ from the first cycle.

Some research studies have shown that the contents of dialogue journals have positive value for students' learning (Konishi \& Park, 2017; Safari, 2020). Safari (2020) conducted a qualitative study in the Iranian EFL context using observation, interview, and analysis of students' entries to explore DJW effectiveness on language learning and critical literacy skills. The study found out that DJW allowed students to use language for narrating their real-life stories and live experiences. It also created a liberating space for students to speak their ideas, voices, and thoughts freely. Moreover, DJW developed students' linguistic knowledge and enhanced their awareness. Konishi and Park (2017) applied DJW as an effort to improve children's healthy social-emotional growth. They believed that the process of social-emotional learning in DJW enables the students to express their feeling freely. They stated that DJW "allows the student to express his or her feelings and thereby, explore emotions with the teacher during the learning process which is crucial to the child's well-being" (p. 247). Konishi and Park emphasized that students can be encouraged to express their individual feelings and concerns without fear through journaling.

The findings found in the aforementioned studies support one another. However, there is a lack of evidence of how exactly DJW affects students' writing performance. In the previous studies, DJW focused on the types of corrective feedback, and the improved score resulted from the provided feedback. Meanwhile, studies on ODJW emphasized psychological aspects like anxiety and attitudes. Therefore, the 
present study tries to complete the gap found in the previous studies by examining the effect of ODJW on students' writing productivity. Conforming to the development of technology, the ODJW was applied to shed light on the contribution of Internet applications to DJW practices. Moreover, students' perception of their writing proficiency is explored.

\section{METHOD}

The present study was aimed to find out the effect of the application of ODJW on the students' writing productivity. It applied a pre-experimental research design as it involved only one group of students whose writing products were evaluated before the ODJW was applied and after the students completed their ODJW activity by looking into their ODJW products. In addition, the study also investigated the students' responses toward the application of ODJW. Thus, it also applied a descriptive qualitative research design.

This study involved 22 students of the English Department of a reputable university in Malang City, Indonesia. The students attended Paragraph Writing course, which lasted for 32 sessions. In this course, the students were taught to write paragraphs that vary from narrative, descriptive, and expository paragraphs. In the last five sessions, the students were involved in ODJW. The theories on "Journal Writing" from Oshima and Hogue (2007: 181-183) were adopted as a guideline in applying ODJW. Two rules about the writing of the dialogue journal were informed to the students: First, each of the students was asked to propose a topic for the ODJW. Some of the topics were taken from the list of 33 topics suggested by Oshima and Hogue (2007: 182-183), and some were the students' own topics. The students were asked to propose the topics through the WhatsApp group so that all of the students knew the list of the proposed topics. Because there were only five sessions, 15 topics were selected from the list, and three topics were announced to the students in each session so that they could choose one topic from the list of three topics. The list of topics was shown in Table 1.

TABLE 1 THE LIST OF TOPICS FOR ODJW

\begin{tabular}{|l|l|l|}
\hline Session & No & Topics \\
\hline \multirow{4}{*}{1} & 1 & My hobby (hobbies) \\
\cline { 2 - 3 } & 2 & My favorite food \\
\cline { 2 - 3 } & 3 & A special skill (special skills) that I have \\
\hline \multirow{2}{*}{2} & 4 & An accident \\
\cline { 2 - 3 } & 5 & A comfortable place \\
\cline { 2 - 3 } & 6 & A special gift you have given or received \\
\hline \multirow{2}{*}{3} & 7 & A story from my childhood \\
\cline { 2 - 3 } & 8 & A special day in my life \\
\cline { 2 - 3 } & 9 & An event in my school life \\
\hline \multirow{2}{*}{4} & 10 & Spending time with friends \\
\cline { 2 - 3 } & 11 & Going to a mind-refreshing place \\
\cline { 2 - 3 } & 12 & Shopping priority list \\
\hline \multirow{2}{*}{5} & 13 & A movie star/artist that I admire \\
\cline { 2 - 3 } & 14 & My favorite sport/exercise to play \\
\cline { 2 - 3 } & 15 & Music/musician/singer that is special to me \\
\hline
\end{tabular}

Second, the students' journal entries should be written in the form of paragraphs so that the students could apply the theories when writing a paragraph. For example, a paragraph should start with a topic sentence which is then supported by supporting details. However, unlike in the regular paragraph writing activities, which require the students to write only one paragraph in one task, in the ODJW, the students were allowed to write more than one paragraph in one journal entry. 
Data on the EFL students' writing productivity was counted from the average number of words in their journal entries. The number of words was counted from the first to last journal within the five-time journal submissions. Data on the students' perception of the application of ODJW were taken from the students' responses on the prompt of paragraph writing given after the ODJW was over. The prompt asked them to write about their perception of their understanding of journal writing, topic preference, good aspects of journal writing, and the students' feelings when writing a journal. The writing prompt is shown in Figure 1.

\section{FIGURE 1 \\ THE PROMPT FOR PARAGRAPH WRITING}

Instruction: Write a paragraph in good English on the topic "My Journal Writing Activities" in 10-12 sentences, including the topic sentence. Following the topic sentence, develop your paragraph by putting the answers to the following questions:

a. What do you understand by journal writing?

b. How do you like the topics of journal writing?

c. What good things did you find from journal writing activities?

d. How did you feel when writing a journal (journals)?

Data of students' writing productivity were based on the number of words of each of the five journals from ODJW activities. The data were analysed by applying two general steps. First, the average number of words in the paragraphs the students wrote in the regular paragraph writing activities was compared to the average number of words in their ODJW activities. The average number of words from the regular writing was determined from the two types of paragraphs that the students wrote, namely Comparison/Contrast Paragraph and Definition Paragraph. These types of paragraphs were chosen because they were the last two types of paragraphs that the students wrote before writing their ODJW. Then, a statistical analysis was used to know whether or not there was a significant difference in the number of words in the two types of writing activities. Meanwhile, content analysis was applied to analyze the data on the students' perception of the application of ODJW. The results of the analysis are presented in the form of a description.

\section{FINDINGS}

The results of the study are presented as the answers to the two research questions: the first is on the improvement in the EFL students' writing productivity after being taught by using ODJW and the second is their perception of the application of ODJW in the teaching of paragraph writing.

\section{EFL Students' Writing Productivity as a Result of ODJW}

Analysis of the number of words of the students' regular writing activities showed that average number of words in the students' Comparison/Contrast Paragraph was 216 and the average number of words in their Definition Paragraph was 178. Meanwhile, the average number of words in the students' ODJW was 273, 290, 321, 255, and 303 from ODJW 1 to ODJW 5, respectively. The record of the number of words that the students wrote in both regular writing activities and ODJW is shown in Appendix 1. The comparison of the number of words in students' regular activities and ODJW is shown in Figure 2. 


\section{FIGURE 2}

\section{WORD NUMBER IN STUDENTS' REGULAR WRITING AND IN ODJW}

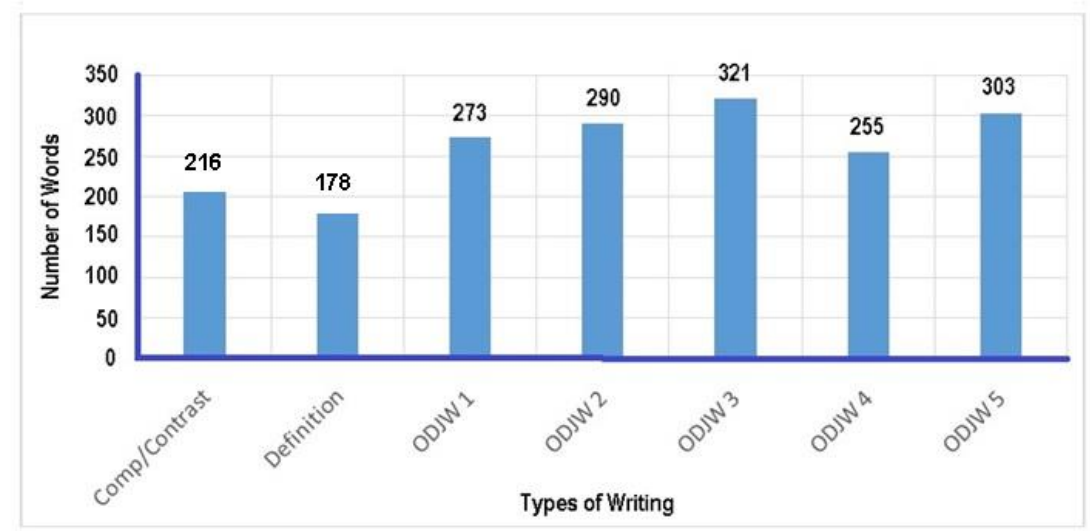

Figure 2 shows a fluctuation in the average number of words that the students wrote in their paragraphs. However, in general, the paragraphs in the ODJW have a higher number of words than the paragraphs in the regular writing activities. Further analysis showed that the average number of words in the students' two regular writing tasks was 204.5, while the average number of words in the students' five ODJW was 288.4. Thus, the number of words increased at the average of 84 words (41\%) from regular writing tasks to ODJW.

Further analysis resulted in the record of the increasing number of words that most of the individual students have written in the ODJW. The comparison of the individuals' number of words in the two kinds of writing is shown in in Figure 3.

FIGURE 3

\section{WORD NUMBER IN INDIVIDUAL STUDENTS' REGULAR WRITING AND ODJW}

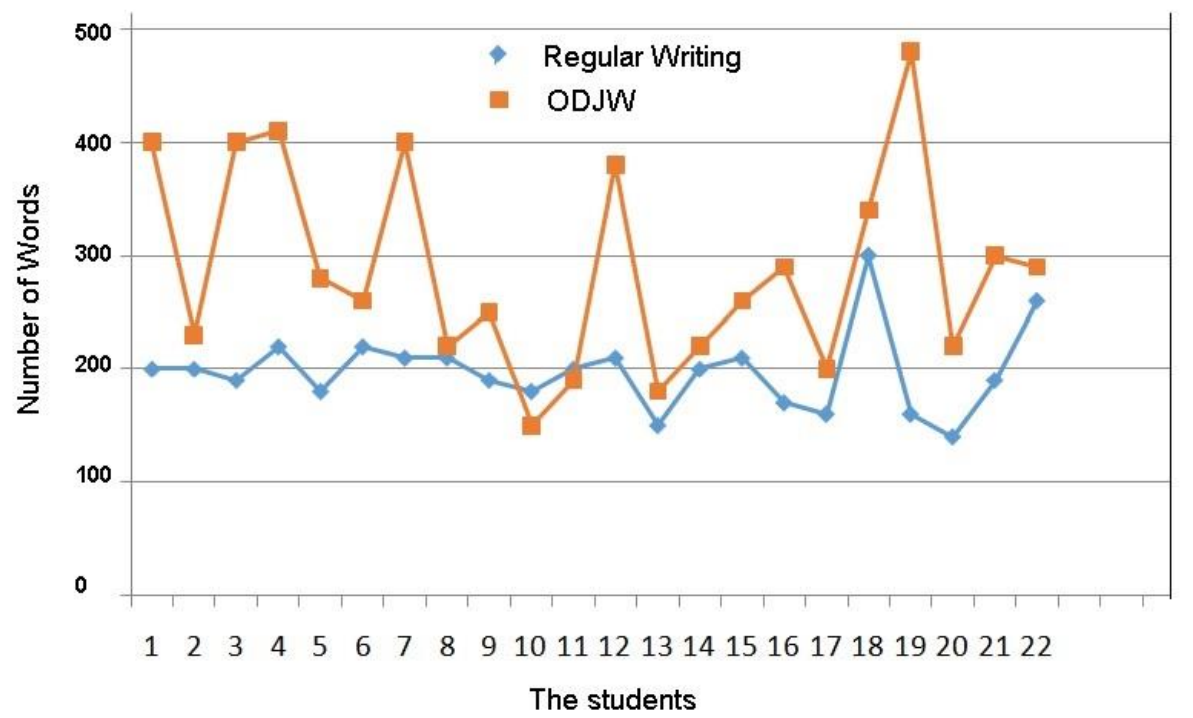

As shown in Figure 3, compared to the number of words that individual students have written in regular writing, the increasing number of words in ODJW happened to 20 out of 22 students. A striking increase in the number of words was found in six students (Students 1, 3, 4, 7, 12, and 9). Meanwhile, one student 
(Student 8) was stagnant, and 2 students (Students 10 and 11) were found to have written a fewer number of words,

Further analysis was conducted by comparing the average number of words written by all of the students in regular writing and in ODJW. The average number of words of the students in the two types of writing activities can be seen in the Appendix. Before a statistical analysis was conducted, a normality test was used to analyse the number of words in the students' regular writing and ODJW. The result of normality test shows that the number of words in the regular writing and ODJW were not normally distributed ( $\mathrm{p} \geq$ 0.05). This indicates that the statistical test used should be the non-parametric one. Therefore, the statistical comparison of the number of words in the two types of writing were performed by using Mann-Whitney test. The result of the comparison shown in Table 2.

TABLE 2

COMPARISON OF THE NUMBER OF WORDS

\begin{tabular}{|l|r|r|r|r|}
\hline & Mann-Whitney U & Wilcoxon W & Z & $\begin{array}{c}\text { Asymp. Sig. (2- } \\
\text { tailed) }\end{array}$ \\
\hline Means & 82.500 & 335.500 & -3.744 & .000 \\
\hline
\end{tabular}

$\mathrm{p} \leq 0.05$

Table 2 shows that there was a significant difference in the average number of words in the students' regular writing and ODJW.

\section{The Students' Perception Toward the Implementation of ODJW}

The students' perception toward the implementation of ODJW was based on two main issues: the good things about ODJW and the feeling the students had when they were engaged in ODJW. All of the 22 students (100\%) answered the question about the good things they found about ODJW, and 21 students (95\%) answered the question on how they felt when they engaged in ODJW.

In general there are two good things that the students expressed with regard to the ODJW activities. First, the students thought that by writing online journals they could reflect on their stories or experiences they did in the past. This is apparent from some of the students' statements. Student 1 stated,

The interesting thing when writing a journal is that it can provide the story that I have experienced to the readers.

In addition, Student 14 exposed,

The good thing that I found in writing a journal is that I can recount the experiences that happened in my life while at school, at home, on vacation, and so on.

The two statements represent the ideas stated by six other students.

The other good thing of ODJW was that the students could practice their writing skill as part of the ways to improve their English learning. Student 4 confessed,

I think journal writing is good to increase the fluency of writing since I can write as many as I want without worry that I will make any mistakes. But still I have to pay attention to the grammar and other rules of writing.

In different words, Student 5 explained, 
I found many good things from journal writing activities, one of them is that I can write any ideas that come from my mind without limitation.

Similar points were also admitted by 15 other students who emphasized improvement in their writing skill in relation to other aspects such as awareness of errors, confidence, creativity, enjoyable process, speed in writing, and vocabulary improvement,

In terms of the student' feelings of the implementation of ODJW, it was revealed that most of the students felt happy or excited. For example, Student 11 expressed,

When I am writing a journal I feel happy because it is a very exciting and interesting thing to do.

In different words, Student 6 claimed,

I feel like I can overflow everything I feel that I cannot express in utterance when writing a journal.

Many other students expressed their feelings by using various words which were dominated by adjectives such as calm, comfortable, enjoyable, extraordinary, free, intrigued, and satisfied. However, there are two students who expressed their unfavourable feelings. Student 17 stated,

I often feel bored and sleepy when I do my journal. On the other hand, I am excited to write about my experience.

Student 21 mentioned,

Sometimes happy or confused because sometimes confused when I determine the topic to write and the pleasure when I succeed and produce good work in writing my journal.

In short, the students found that ODJW was good in that the writing activities could help them remember their past experiences and help them improve their writing skills. In addition, while few students had some boredom or confusion, the majority of the students have pleasant feelings with regard to the implementation of ODJW.

\section{DISCUSSION}

The results of the study revealed that the implementation of ODJW encouraged the students to write more productively. This was evident in the average number of words in the paragraphs they have written in ODJW that exceeds the average number of words of the paragraphs they have written in regular paragraph writing activities. This may be caused by two factors. First, the students have realized that writing dialogue journals does not end in the delivery of the messages in the paragraph, but there is an expected response of the lecturer as the target audience. The first entry in the dialogue journal is not the only text, but it is an initiation that is responded to by the lecturer. The students could write even more productively if they followed up on the lecturer's responses before writing a new dialogue journal entry. Therefore, the communicative nature of the ODJW could lead to more intensive interaction between the students and the lecturer. This conforms to Zone of Proximal Development in Vygotsky's socio-cultural theory which states that "mental functions that are beyond an individual's current level must be performed in collaboration with other people before they are achieved independently" (Saville-Troike, 2006, p. 112). Thus, as argued by Rana (2018), the practice of dialogue journal writing supports second language acquisition.

The second factor is the more comfortable feeling that makes the students write more. ODJW, like the common journal writing, helps the students "acquire a level of fluency in written language" (Oshima \& 
Hogue, 2007, p. 181). This is because, in ODJW, the students focused on the content so that they did not worry about the use of accurate grammar or sophisticated vocabulary. As emphasized by Peyton and Reed (1990) that there should be no corrections or criticism in language use, students could be free in pouring what they thought and felt through ODJW. This was reflected in the most of the students' pleasant feelings when writing their journals. The comfortable feelings might also come from the content of the journals which were centralized on the students' own experiences. So, as the students have pointed out in their ODJW they enjoyed writing their past experiences. The uncomfortable feelings of some of the students might come from their unfamiliarity with the rules in ODJW. As Baskin (1994) stated, possible confusion among students in the implementation of dialogue journal writing may result from the fact that the students did not know that could write freely or that the lecturer would give responses to what they write. This might have been experienced by the students who did not make any increase in the number of words in their ODJW.

The finding of this study supports the study conducted by Konishi and Park (2017), who found that DJW promotes a positive social-emotional learning environment. It was known from the present study that the majority of the students revealed to have pleasant feelings when they were involved in ODJW. They expressed it using several adjectives such as calm, comfortable, enjoyable, extraordinary, free, intrigued, and satisfied. This indicates that a positive social-emotional learning environment emerges during the implementation of ODJW. Although this study did not distinguish students' proficiency levels as conducted by Madeng and Palanukulwong (2019), the increasing number of words on students' writing production from regular writing activities to ODJW revealed that the students were more willing to write. Nevertheless, since few students were found to have either a stagnant or less number of words, it can be assumed that there were some factors underlying the phenomenon, which might be proficiency level, or more specifically, limited vocabulary (Hapsari et al., 2018).

In contrast to the study conducted by Nuramirah (2017), in which there was an employment of corrective feedback to the students' dialogue journal writing, this study did not provide any overt correction to show students' mistakes. This study, however, followed the early practice of DJW (Peyton \& Reed, 1990; Baskin, 1994). It was instead focused more on the students' writing productivity than their writing score, which is believed to have a relationship with corrective feedback. The traditional implementation of DJW seems to affect students' productivity in such a way that they boost the number of words in ODJW. The absence of correction to their writing might be one of the factors causing the increase of productivity and students' pleasant feelings, as revealed by their responses toward the writing prompt in a nonthreatening atmosphere (Hapsari et al., 2018). However, students mentioned that they still pay attention to the grammar and other rules of writing. It indicates that without any overt correction, students were aware of producing good writing. This means that the monitor hypothesis worked during the writing process in ODJW.

Regarding the students' ODJW contents, the list of topics such as my hobby, a comfortable place, a story from my childhood, and others encouraged them to recall and reflect on their life experiences. Therefore, students have the opportunity to use language to pour their real-life stories into narration (Safari, 2020). Since the topics were related to personal experience, it was easier for them to generate ideas for their ODJW. Thus, the students were able to produce more words in their ODJW. Thus, it can be assumed that their writing productivity might be affected by the familiarity of writing topics.

\section{CONCLUSIONS}

The study has revealed that, in general, ODJW encouraged EFL students to write more productively. The students recognized that they had the opportunity to convey ideas and thoughts in ODJW, which is essentially different from the regular writing activities. In addition, they thought that ODJW was beneficial in rejoicing their mind as they could share their past experience and at the same time develop their skills in writing. They also felt happy with practices in writing the dialogue journals. It should be noted that while most of the students could write more productively, only some of the students could show a dramatic increase in the number of words they have written in ODJW. However, this preliminary study did not 
examine the reasons why some other students seemed to develop more slowly, to be stagnant, or even to digress in the number of words. Therefore, further research could find the reasons behind the phenomena by answering the question of whether the technological tool applied in ODJW was among the reasons. It is also important to find out why few students got confused or bored by the time they had to write their ODJW. The answers to these questions could enrich the discussion in the use of dialogue journal writing in online setting. Considering that many Internet applications have not been used for ODJW, other research studies could also explore the use of certain Internet applications or investigate the effects of certain applications in dialogue journal writing on EFL learning achievement.

\section{REFERENCES}

Al Kayed, M., Alkayid, M., \& Alsmadi, M.A. (2020). The impact of dialogue journal writing on the writing skills of Jordanian EFL learners and their attitudes towards writing. Humanities \& Social Sciences Reviews, 8(4), 569-576.

Baskin, R.S. (1994). Student feedback on dialogue journal. ERIC Document No. ED 375-627/FL-022459. Retrieved January 28, 2021, from https://files.eric.ed.gov/fulltext/ ED375627.pdf

Dabbagh, A. (2017). The effect of dialogue journal writing on EFL learners' descriptive writing performance: A quantitative study. International Journal of Applied Linguistics \& English Literature, 6(3), 71-80.

David, A.R., Azman, H., \& Ming, T.S. (2018). Investigating online dialogue journal writing impacts on low proficiency students' writing anxiety. International Journal of Language Education and Applied Linguistics (IJLEAL), 8(2), 71-81.

Hapsari, Y.W., Susilohadi, G., \& Elyono, D. (2018). Using dialogue journal to improve students' writing proficiencies. English Education Journal, 6(3), 379-388.

Konishi, C., \& Park, S. (2017). Promoting children's healthy social-emotional growth: Dialogue journal. Journal of Education and Learning, 6(2), 246-253.

Madeng, M., \& Palanukulwong, T. (2019). Low proficiency students' attitudes toward English writing, dialogue journal writing and their willingness to write in English. Academic Services Journal Prince of Songkla University, 30(3), 110-120.

Noyan, E., \& Kocoglu, Z. (2019). Developing EFL writing skills through WhatsApp dialogue journaling. Advances in Language and Literary Studies, 10(2), 38-48.

Nuramirah, P. (2017). An analysis of teacher's corrective feedback and learners' uptake in dialogue journal. Advances in Social Science, Education and Humanities Research (ASSEHR), 82, 308310.

Oshima, A., \& Hogue, A. (2007). Introduction to academic writing ( $3^{\text {rd }}$ ed.). White Plains, NY: Pearson Education.

Peyton, J.K., \& Reed, L. (1990). Dialogue journal writing with nonnative English speakers: A handbook for teachers. Alexandria, Virginia: Teachers of English to Speakers of Other Languages (TESOL).

Rana, L.B. (2018). The use of dialogue journals in an ESL writing class from Vygotskyan perspective. Journal of NELTA Surkhet, 5, 1-14.

Safari, P. (2020). Constructing an emancipatory learning environment in Iranian English classes through dialogue journal writing as an educational tool. Education, 3-13, 1-17.

Saville-Troike, M. (2006). Introducing Second Language Acquisition. Cambridge: Cambridge University Press. 


\section{APPENDIX: NUMBER OF WORDS IN THE STUDENTS' REGULAR WRITING AND ODJW}

\begin{tabular}{|c|c|c|c|c|c|c|c|c|c|}
\hline \multirow{2}{*}{$\begin{array}{c}\text { Std } \\
\text { No }\end{array}$} & \multicolumn{3}{|c|}{ Regular Writing } & \multicolumn{5}{c|}{ Online Dialogue Journal Writing } \\
\cline { 2 - 10 } & $\begin{array}{c}\text { Comp/ } \\
\text { Con }\end{array}$ & Def. & Average & $\mathbf{1}$ & $\mathbf{2}$ & $\mathbf{3}$ & $\mathbf{4}$ & $\mathbf{5}$ & Average \\
\hline 1 & & & & & & & & \\
\hline 2 & 200 & 203 & 202 & 278 & 547 & 492 & 264 & 413 & 398 \\
\hline 3 & 257 & 125 & 191 & 426 & 348 & 533 & 253 & 456 & 403 \\
\hline 4 & 223 & 221 & 222 & 370 & 541 & 466 & 314 & 348 & 408 \\
\hline 5 & 159 & 190 & 175 & 361 & 278 & 302 & 229 & 251 & 284 \\
\hline 6 & 235 & 209 & 222 & 197 & 266 & 277 & 282 & 251 & 255 \\
\hline 7 & 220 & 202 & 211 & 321 & 439 & 416 & 439 & 402 & 403 \\
\hline 8 & 231 & 193 & 212 & 252 & 187 & 193 & 170 & 273 & 215 \\
\hline 9 & 198 & 178 & 188 & 248 & 283 & 154 & 261 & 321 & 253 \\
\hline 10 & 233 & 118 & 176 & 168 & 170 & 129 & 124 & 175 & 153 \\
\hline 11 & 217 & 178 & 198 & 160 & 204 & 215 & 165 & 219 & 193 \\
\hline 12 & 203 & 206 & 205 & 258 & 284 & 483 & 431 & 459 & 383 \\
\hline 13 & 136 & 161 & 149 & 148 & 170 & 222 & 157 & 177 & 175 \\
\hline 14 & 241 & 167 & 204 & 157 & 129 & 427 & 190 & 183 & 217 \\
\hline 15 & 265 & 151 & 208 & 202 & 317 & 310 & 224 & 240 & 259 \\
\hline 16 & 188 & 142 & 165 & 310 & 319 & 267 & 289 & 256 & 288 \\
\hline 17 & 148 & 170 & 159 & 214 & 286 & 138 & 192 & 172 & 200 \\
\hline 18 & 374 & 234 & 304 & 253 & 360 & 431 & 251 & 381 & 335 \\
\hline 19 & 163 & 161 & 162 & 714 & 231 & 544 & 337 & 553 & 476 \\
\hline 20 & 161 & 114 & 138 & 224 & 316 & 216 & 173 & 173 & 220 \\
\hline 21 & 250 & 132 & 191 & 316 & 246 & 327 & 307 & 307 & 301 \\
\hline 22 & 258 & 258 & 258 & 234 & 302 & 252 & 294 & 377 & 269 \\
\hline Total & 4758 & 3917 & 4341 & 6007 & 6378 & 7062 & 5602 & 6679 & 6321 \\
\hline Mean & 216 & 178 & 197 & 273 & 290 & 321 & 255 & 303 & 287 \\
\hline & & & & & & & & & \\
\hline
\end{tabular}

